\title{
The Use of Deductive and Inductive Approaches in Teaching Grammar for Afghan University Students of English and Literature Studies
}

\author{
Shahzadgul Ahmadzai, Rahmatullah Katawazai, Sandaran, SC
}

\begin{abstract}
Teaching English language started with using the traditional teaching methods in the educational system of Afghanistan. Teachers preferred such kinds of classical methods for teaching grammar as well. To the knowledge of the researchers, there is a lack of research conducted to indicate whether the two common methods for grammar teaching, i.e. inductive or deductive, are more effective within the Afghan teaching and learning context. The current study has been conducted to find out the effectiveness of using inductive and deductive teaching approaches to teaching English grammar in the Afghan context. Using a mixed-method (qualitative and quantitative) approach for data collection as well as analysis, the study conducted a questionnaire survey of 218 students and 13 instructors and semi-structured interviews with 4 language instructors from both English Departments of Education \& Literature Faculties at a university in Afghanistan. The findings indicate that there is no significant difference of using one approach over another and Afghan students can learn through both deductive and inductive approaches in teaching grammar. However, from the perspective of the teachers, it was found that the teachers generally prefer the deductive method and rarely use the inductive method as they are trained in the classical method of teaching English. The findings of the study will help English grammar teachers to view the importance of using both of the teaching methods in Afghan context in order to make learning grammatical rules and its structures easy for the students to overcome.
\end{abstract}

Keywords: Deductive Approach, Inductive Approach, Teaching Grammar, Kandahar University, Afghanistan

\section{INTRODUCTION}

English is one of the school's compulsory subjects starting from primary education up to advance level of language in Afghanistan. With the economic downturn in Afghanistan for the last three or four decades, the education system in the country has declined, but currently, a large number of companies and educational institutions in Afghanistan have embraced cooperation at regional and international levels Thus, more importance is being given to the English Language, currently. English is used as the means for communication, negotiation, and execution of the transaction between speakers inside or outside of the country between native and non-native speakers. However, Afghans' level of English proficiency is low in contrast with many other countries in Asia such as India, Malaysia, and Singapore. One

Revised Version Manuscript Received on April 19, 2019.

Shahzadgul Ahmadzai Faculty of Education, Department of English, Kandahar University, 3801, Kandahar, Afghanistan

Rahmatullah Katawazai Faculty of Languages \& Literature, Department of English, Kandahar University, 3801, Kandahar, Afghanistan

Sandaran, SC Language Academy, Universiti Teknologi Malaysia, 81310, Johor Bahru, Johor, Malaysia

reason for this is that English language teaching in Afghanistan has not prepared Afghans for the changing world.

In Afghanistan, English language is taught mainly by Afghan teachers and English appears to be taught through the Afghan language(s) as the medium of instructions. The lessons are limited to grammatical points and comprehension reading which require heavy explanations via use of mother tongues and the national language. Moreover, many language teachers are used to the traditional style of language teaching as they themselves were taught via such methods at school. This is especially so with the teaching of grammar. For example, a teacher explains the rules of the language and tries to make learners understand and memorize them. Due to the fact that the students only study English to pass school exams, they are not well-motivated and are deprived of the opportunities to practice English in real life situations. They are not able to communicate effectively in English due to numerous factors.

In this regard, the focus of this research is on grammar teaching and specifically on the two methods (deductive and inductive) that are generally used for grammar teaching in the classroom. Selecting the appropriate method of teaching grammar is difficult for instructors because students have various types of styles of learning a particular language, especially English. Thus, this study aims to investigate the perceptions of Afghan English language teachers and students about the use of the inductive and deductive methods for the teaching of grammar.

Researches on the use of deductive and inductive approaches of teaching grammar have been conducted in various contexts [1]-[2]-[3], however within the Afghan context, to the knowledge of the researchers, there is a lack of research. In fact, it can be stated that while there have been lots of research on ELT globally, not much has been investigated about the teaching and learning of English Language in Afghanistan. Thus, to get a better understanding of the practices of EFL within the Afghan context, we focus on the strategies for teaching of grammar, i.e. inductive and deductive approaches.

Similar studies have been conducted on the effectiveness of inductive and deductive methods for teaching grammar. For example, Zamani A and Mohammadi stated that there are no significant differences between the two approaches for 
Iranian students when they learn English[4]. Chalipa on the other hand, expressed that inductive instruction is extremely beneficial and highly motivating for students' comprehension of materials presented to them [5]. This shows that the methods have different outcomes in different contexts. To this end, we look at the use of the approaches for grammar teaching within the Afghan context and more specifically, for university students of language and literature studies. We hope the findings would provide a better understanding for Afghan EFL teachers, about more effective methods for grammar teaching.

The study hopes to answer the following research questions:

- 1. What are the perceptions of Afghan teachers about using deductive and inductive methods of teaching grammar in the classroom?

- 2. Which approach of teaching grammar is preferred by the teachers?

\section{LITERATURE REVIEW}

1) Differences between Inductive and Deductive Approach in Teaching Grammar

Researchers and most instructors pay much attention to grammar instructions because they have found positive outcomes of grammar instruction in their empirical and classroom-based studies [4]. Moreover, teaching grammar is an instructional technique that draws learners' attention to some particular grammatical form in such a way that helps them either to understand it meta-linguistically or process it in comprehension or production so that they can internalize it. Using appropriate teaching methods helps students to gain experience in grammar and also in learning English because the attitude and desire of students are different from each other. Thus, students should be prepared psychologically to acquire English as a second or foreign language [6].

In order to understand the teaching of grammar, the most useful and effective methods are the inductive and deductive approaches. Both approaches can be basically differentiated through the lesson procedures, learner roles, teacher roles and usage of meta-language in the teaching process. Inductive teaching is based on the bottom-up theory which accepts the view that language learners tend to focus on parts rather than the whole. For this reason, the teaching process begins with a text, audio or visual in a context. Secondly, learners work on the materials to find the rules themselves. In the final stage, they give their own examples. In contrast to this, a deductive approach is based on the top-down theory where the presentation and explanation of grammar rules take precedence over teaching. The language is taught from the whole to parts so learners understand the grammar rules and structures in first. Next, they see the examples provided by the teacher and finally, they begin to produce their own examples.

Consequently, students are passive recipients in the deductive method because it is the teacher who elicits the rules and gives information to the students. However, students are more responsible in the inductive approach in order to explore rules for themselves. It is to say that learning is more experiential in the inductive approach, but it is more traditional and descriptive via the deductive approach. Thornbury suggested that involving students actively in the lesson can prepare students to be more comfortable and provide them a motivated environment [7]. It has been stated that actively involving students in their learning process enhances their autonomy which makes them good language learners [8].

Using inductive and deductive approaches in teaching grammar is dependent on students' needs as all learners prefer different ways of learning grammar. For instance, age, need, background, level, and cultural difference are the main issues to be considered for choosing the appropriate teaching approach to teaching grammar. To illustrate this, adult learners tend to deal with the rules when they use the target language since their mind is able to think abstract items. Regarding this, deductive teaching is more suitable for adult learners and meets their expectations as they give more priority to rules when they use the language so the presentation of grammar rules first is more useful for them. On the other hand, young learners pay more attention to exploring grammatical structures from the examples rather than learning them deductively since they are more likely to learn by doing because grammar rules are complex and abstract for them [9].

Mahjoob conducted a study of over sixty students to investigate the effectiveness of the two approaches. The study highlighted that both of the approaches played a vital role in the outcome of teaching grammar, but there was a slightly significant effect of the inductive approach [10]. Similarly, Keijzer pointed out that, both the inductive and deductive methods have a positive outcome for Dutch pupils who were learning English in schools. However, the deductive method turns to be the most effective for long term learning. Students have learned the rules first rather than acquiring rules [11] Britton however stated that there is no significant difference between the two methods [12]. Sik mentioned that both of the approaches have crucial roles in the learning of a language and instructors can use them according to the level, condition, and preference of their students, but deductive approach is slightly effective for their students [13]. The inductive and deductive approaches have been increasingly discussed over the years. The term inductive is most useful when a child learns its first language through exposure to the language in use. The inductive method should be used when teaching relatively simple grammatical structures because the method is too difficult. Neither of the techniques was found to be more practical with simple grammatical structures, but the deductive approach is said to be more successful when teaching more complicated structures [14]. Our study draws upon these studies to investigate the effectiveness of the approaches within the Afghan EFL context.

\section{METHODOLOGY}

The study uses a mixed-method (qualitative and quantitative) approach. 218 students (aged $18-25$ ) and 13 teachers (with 5-7 years of teaching experience) from two 
English Departments of the Faculties of Education and Language and Literature at a university in Kandahar, Afghanistan, took part in the study. For the quantitative part, we adopted Nesic \& Hamidovic's questionnaire [15]. There were five items in the questionnaire which consists of strongly agree, agree undecided, disagree and strongly disagree. It was prepared to evaluate students' perception about inductive and deductive approaches. And for the qualitative part, semi-structured interviews were conducted with 4 English Language teachers from the two departments. The quantitative data was analysed using SPSS 24. And the semi-structured interviews are explained based on descriptive statistics, based on percentage of agreement, disagreement, and etc.

\section{FINDINGS AND RESULTS}

\section{Quantitative Findings (Students' Perceptions)}

The findings based on 218 respondents (students) via questionnaire are discussed in this section. The questionnaire uses Likert scale type questions with categories from strongly agree to strongly disagree, with statements related to the two approaches to grammar teaching and their preferences to the approaches.

The majority of the respondents stated that that they learn grammatical structures better when the teacher gives explanations about the structures $(56 \%$ of the respondents strongly agreed while $36 \%$ agreed). Similarly, almost all of the respondents strongly agreed or agreed that they prefer to learn grammatical structures through the use in examples of sentences. Only a small number (3\%) disagreed to the teaching of grammatical structures via the use in sentences as they found them to be less effective for the learning of grammar in general. Again most of the respondents either strongly agreed or agreed that they preferred learning to practice sentence structure in context, while again a small number $(3 \%)$ strongly disagreed to this. In contrast, almost half of the respondents indicated their preference for the deductive method for the teaching of grammar.

Once again, half of the respondents stated that they are able to learn sentences when they use it in a particular structure. This type of learning relates to the deductive teaching approach where an instructor explains the rule first and then includes practice sentences for the mentioned rule. It should also be noted that this is an explicit learning process where the students first focus on the form then its practice in sentences. Almost half of the respondents strongly agreed that they wanted to improve their sentences when they use it in a specific structure. On the other hand, only $5.5 \%$ of the participants were indecisive on whether implicit learning of structures is helpful. It could be that they may have not experienced this type of learning process. A small of respondents do not prefer to learn sentences when they are used in a particular structure. Almost half of the respondents strongly agreed $(63 \%)$ and agreed $(30 \%)$ that they prefer to learn grammar through sentence structures when they are used in context as this is more effective and helps them understand the rules and their uses. This type of teaching scenario is based on inductive teaching of grammar, where the learners

actively use a grammatical structure in its real situation. The learners can identify its real place of the usages. Again, about $16 \%$ were indecisive about learning grammar through sentence structure within context. The reason for this could be that the students are not familiar with the approach or that they are just not interested in learning grammar.

98 out of the 218 students stated that they are interested in using sentences in different situations. Out of this, almost half stated that they prefer to identify a particular situation or the sentence in a language. This means, if the teachers show them the usage of a sentence in its own situation, it is more comprehensible for them then if the teacher just explains to them the structure of a sentence. Again a small number of students are not aware of these approaches to grammar teaching or do not prefer to learn the use of grammar through sentences in different situations, as some of them disagreed/strongly disagreed to learning grammar through sentences used in its real-life situations.

About $30 \%$ of the respondents chose the inductive rather than the deductive approach to learning grammar as they preferred the lecturers to use this approach. An equal number of respondents said that they want to learn through the deductive approach. Once again, a small number of respondents were indecisive and stayed neutral. In fact, they stated that they do not see any significant differences between the two methods and prefer if the instructors could use both of approaches when teaching grammar. This means that the students' view both the learning of grammar rules explained by the teachers, or through acquiring from examples as being beneficial for them. However, there are some (12.4\%) who prefer one method over the other. Here it is worth noting that it would be good for lecturers to alternate between the two methods when teaching grammar in order to suit the needs of the students as some of the students may learn grammar structures better via the inductive approach while the deductive approach could meet the needs of rest of the students. This could also help the students who are indecisive on the better approach as it could be that they are either not aware of the two approaches or have little interest in learning grammar.

\section{Quantitative Findings (Teachers' Perceptions)}

In this section, we discuss the findings based on the teachers' perceptions about the use of the two approaches when teaching grammar to Afghani English university students of English and Literature Studies.

In general, most of the teachers agreed that grammar should be taught through the use of examples and exercises for practice, which is the explicit method of teaching grammar. When teachers explain grammatical rules and follow up with examples in sentences for practice, this relates to the deductive method, which is a more teacher centered approach. On the other hand, more than half of the teachers agreed that teaching grammar in context is more effective and meaningful for learners, which relates to the inductive approach. Thus, it can be said that the teachers in general 
favor certain elements of both approaches. Most of the teachers agreed to learning of grammar where the teachers show their students the use of sentences in various situations, and for them to explain the different parts of the sentences. This relates to the inductive teaching method and most of the teachers use this kind of process for enhancing meaning based learning. This is a student centered approach. Overall, all of the teachers were unanimous that the students can learn better sentence structure when the teacher shows their use in real-life situations. When asked which approach is better, an equal number favored one over the other, which means half preferred the deductive approach while the other, the inductive. As such, half of the respondents said that there is a significant difference in students' results when using the inductive method over deductive method. Similarly, other half vouched for the deductive approach. It is worth a mention that within the Afgani context, it is the teachers' preference that seems to of significance on which approach is used.

\section{Qualitative Findings: Teachers' Perceptions}

Following the teachers' perceptions of the use of the two approaches discussed above, and the outcome that the teachers' preferences seem to be the key factor when deciding on the right approach for the learners, we conducted 4 semi-structured interviews to get a more in-depth understanding of their perceptions. The following questions were asked to probe into their perceptions further:

- What is your idea about teaching grammar through context?

- What is your perception about the teacher explaining grammar first and practice it through exercises? Why, why not?

- What is your idea about teaching grammar structures to express it in various situations?

- What is your idea about expressing words and using them in different parts of a sentence?

- Do you agree with that expressing grammatical structure in different situation is more effective than the teacher explains it only with an example?

- Overall, what is your plan to teach grammar if you are a grammar instructor?

- Do you prefer the deductive or inductive method for teaching grammar?

In general, similar to the findings in the qualitative section, the teachers expressed that both of the methods of teaching grammar are needed in the Afghani context. However, as they have been trained under the deductive method, and the students are used to this approach to grammar teaching, they tend to use the deductive method more. It means that although the inductive method is preferred as one of the effective methods to teach grammar, Afghan teachers still rely equally on the deductive method of teaching grammar. But, this does not mean that they do not use the inductive method at all.

In the interviews, the teachers did indicate that they would like to use the inductive method of teaching and to teach not only the grammatical structures, but to motivate students to use these structures communicatively in various types of real-life activities. Research has indicated that the inductive method is more useful than deductive because the inductive

method can include more interactive and interesting teaching methodologies for teaching English, such the Communicative Language Teaching, using syllabus types which are based on the theory of second language acquisition (SLA). Within, Although the inductive approach is often universally assumed to be the better choice, in some Tertiary, Secondary and Primary English Language Schools (TESEP) countries a deductive approach may be more appropriate: "it may be more time-effective, acknowledges local cultural perceptions on language learning, is appropriate for large class sizes, and comfortably accommodates the predominant exam-culture mentality that values accuracy through written testing" [16, pp. 223]. For the Afghan teachers, they explained that do prefer to use the inductive method of teaching grammar because it is interesting, motivating and effective, but they still rely heavily on the classical (deductive) method of teaching grammar due to the constraints of the ELT textbook curriculum, in which most of the grammatical activities are organized in the deductive manner. In fact, they find the inductive method not time-effective as they have large classes and the students are more comfortable with the deductive method. These aspects pose some serious challenges in the Afghan context that prevent teachers to apply the inductive method of teaching for grammar.

\section{V.DISCUSSION}

This study evaluated the use of inductive and deductive teaching approaches in the Afghan context. Inductive and deductive approaches are the two most useful approaches in teaching English grammar to native and nonnative speakers. Regarding this, Long stated that focus on form approach is suitable and applicable for both ESL and EFL learners [17], but Fotos suggested that focus on form is the most conventional and useful approach and it is the best fit for EFL learners [18]. Based on the issue, most of the Afghan instructors have been using form focus or deductive approaches in teaching grammar. Thus, the reason is that Afghan students have more experience in the knowledge of grammar elements; however, they face a problem as they are unable to use this knowledge in their spoken language which is a very essential point to be considered in language learning. According to Azar, both meaningful input and grammar instructions are crucial to improve students' spoken and written abilities [19].

However, contextual or meaningful grammar instruction has had a better result in different cases. It has been mentioned that there is no effectiveness of one method over another method in the Afghan context. It does not mean that the two methods are not different from each other at all. But it means that in the Afghan context, both of the methods can be used. Regarding this, it has been suggested that communicative approaches to teaching grammar have a vital role in the growth of students' writing and sentence structures [20]. This means some of the students can learn through one method over another. Almost half of the students selected the activities which were based on deductive approach, but some 
of the students have chosen the activities which were depended on inductive approaches of teaching grammar.

Additionally, it should be declared that teaching grammar through deductive and inductive approaches is the attitudes and views of Afghan students and teachers. It may be some of the students prefer the deductive approach where teaching mostly depends on the top-down theory of learning which focuses on whole language process, but inductive approaches of teaching based on the bottom-up theory process. This means that Afghan instructors should include visual, audio and other meaningful materials when using the bottom-up process of teaching grammar; and focus on instructions or explanations of grammatical elements when using the top-down process. It is better to involve students actively in their learning process and enable them to become autonomous where students can acquire rules from the examples [8]. The study also considers that it is beneficial for the students to work collaboratively because this provides more input for the students. It proposes that teachers should include spoken language as examples when learning grammar as the young learner can learn grammar better if they hear from spoken language and acquire the language as this is currently missing in the Afghan context. Berendse suggests that young learners can learn better if they hear grammatical structure unconsciously, automatically and correctly in a speech [21].

Furthermore, inductive and deductive approaches to teaching grammar have various results in different countries. It means that one method is useful, has greater motivation and has a better result in one country, but the other method is applicable, is understandable and useful in another country [22]. Besides this, both of the approaches are applicable in some countries. It means that they have equal results in some countries when teachers use inductive and deductive approaches in teaching grammar. The finding of this study also proposes that both the inductive and deductive approaches for teaching grammar are applicable in the Afghan context because of the positive perceptions of instructors and students.

\section{CONCLUSION}

Based on the quantitative findings, students preferred both of the methods of teaching grammar in the Afghan context. However, as explained by the teachers, the students may prefer the deductive method because they are used to the traditional manner of learning English grammar. Additionally, teachers viewed both methods as suitable in the Afghan context. Although the inductive method is also preferred by the students and teachers, Afghan teachers still rely on the deductive method of teaching grammar. But, it does not mean that they do not use the inductive method at all.

The findings from the qualitative part indicate that the teachers really would like to use the inductive method of teaching and to teach not only the grammatical structures, but to motivate students to use these structures communicatively in various types of real-life activities, as suggested in research studies that the inductive method is more useful than deductive it can use a variety of teaching methods (e.g. CLT) based on modern theories of second language acquisition (i.e. SLA).

According to Hinkel and Fotos, inductive approach fosters the mental effort and enables the development of students' mental capabilities, analysis and makes the connection between the segments of speech, thus participating actively in the teaching process [8]. It means that inductive approach of teaching is globally accepted by ELT teachers that students who are trained with inductive method of teaching grammar would have higher proficiency than those who are trained with the traditional methods. But the constraints toward implementing inductive method of teaching grammar in Afghan context include; the ELT textbooks curriculum, in which most of the grammatical activities are organized deductively, inductive method is considered as less time-effective if compared with the deductive method; and large class size, among others. These are the main obstacles faced by Afghan teachers that prevent them applying it in teaching grammar. It means that such kinds of the teaching and learning environment in the Afghan context prevent using the inductive approach of teaching grammar in the process of teaching and learning. The findings of the current study will help policymakers and curriculum developers in Afghanistan to include inductive grammatical activities in ELT textbooks in order to help the teachers use it more frequently. It has to be noted that this study is limited to the perceptions of Afghan ELT teachers and students regarding the use and preference of using deductive and inductive approach of teaching grammar. Therefore, this study recommends conducting more research focusing more specifically on all the constraints and challenges toward implementation of inductive approach of teaching grammar in the Afghan context.

\section{REFFERENCES}

1. Watson AM. Conceptualisations of 'grammar teaching': L1 English teachers' beliefs about teaching grammar for writing. Language Awareness. 2015 Jan 2;24(1):1-4.

2. Mollaei F, Taghinezhad A, Sadighi F. Teachers and Learners' Perceptions of Applying Translation as a Method, Strategy, or Technique in an Iranian EFL Setting. International Journal of Education and Literacy Studies. 2017 Apr 30;5(2):67-73.

3. Al-Harbi SS, Alshumaimeri YA. The Flipped Classroom Impact in Grammar Class on EFL Saudi Secondary School Students' Performances and Attitudes. English Language Teaching. 2016;9(10):60-80.

4. Zamani A, Mohammadi FA. A comparison between using an inductive strategy and a deductive one in grammar instruction for Iranian EFL learners. Enjoy Teaching Journal. 2014 Mar 2.

5. Chalipa S. The effect of inductive vs. deductive instructional approach in grammar learning of ESL learners. International researchers. 2013 Jun;2(2):176-87.

6. Hmedan HA, Nafi JS. The Effect of Using Inductive and Deductive Methods on 7th Grade Students' Achievement in Grammar in Bethlehem District and their Attitudes toward EFL.

7. Thornbury S. How to teach grammar. Harlow: Longman; 1999.

8. Hinkel E, Fotos S, editors. New perspectives on grammar teaching in second language classrooms. Routledge; 2001.

9. Brown, H. D. (1994). Teaching by Principle: An interactive approach to language pedagogy. Englewood Cliffs: Prentice Hall Regents.

10. Mahjoob, E. (2015). A comparison of the effectiveness of inductive vs. deductive instruction of grammar to EFL students. Iran: American Institute of Science, v 1 (5), p. $164-169$. 
11. Keijzer, M.C.J. (2012). A comparison between the effectiveness of inductive and deductive instruction in the L2 English classroom in a L1 Dutch environment. Esther Berendse: Utrecht University.language acquisition: Multiple perspectives. Newbury House, pp. 115-141.

12. Britton GE. A comparison of the inductive and deductive group approaches in teaching selected phonic generalizations to second grade children.

13. Sik K. Tradition or modernism in grammar teaching: deductive vs. inductive approaches. Procedia-Social and Behavioral Sciences. 2015 Jul 25;197:2141-4.

14. Erikson, L. (2014). The effectiveness of modified inductive versus deductive teaching. Engelska: UMEA University.

15. Nešić ID, Hamidović KĆ. Teaching English grammar: Efficiency of inductive and deductive approaches students' perceptions. Zbornik radova Filozofskog fakulteta u Prištini. 2015(45-3):189-205.

16. Mallia JG. Inductive and Deductive Approaches to Teaching English Grammar. Arab World English Journal. 2014 Apr 1;5(2).

17. Long W. Instructed interlanguagedevelopment In LM Beebe (Ed.), lssues in second language acquisition.

18. Fotos, S. (1998). Shifting the focus from forms to form in the EFL classroom. ELT Journal 52(4), 301-307.

19. Azar B. Grammar teaching and communicative teaching: A hybrid that works. Retrieved September. 2006;12:2012.

20. Nassaji $\mathrm{H}$. Towards integrating form-focused instruction and communicative interaction in the second language classroom: Some pedagogical possibilities. The modern language journal. 2000 Jun;84(2):241-50.

21. Berendse, E. (2012). A comparison between the effectiveness of inductive and deductive instruction in the L2 English classroom in a L1 Dutch Environment. Utrecht University.

22. Gollin, J. (1998). Key concepts in ELT: Deductive vs. Inductive Language Learning. ELT Journal, 52, (1), 88-89. 